\title{
Correspondence
}

\section{Need for review of Tribunal and appeals system}

DEAR SIRS

With regard to the numerous letters concerning various aspects of the Mental Health Act recently published I would like to make the following comments:

(a) With reference to Professor Prins' comments (Psychiatric Bulletin, 1991, 15, 640-641) concerning those considered "hopeless" by the Responsible Medical Officer, I must agree with Dr West's point of view (Psychiatric Bulletin, 1991, 15, 641). Having regular Mental Health Review Tribunals, when a patient is quite clearly mentally ill and hospital treatment is essential, is a waste of both time and money in an already hard-pressed health service. Professor Prins adds "to place financial expedience above the protection of such people" etc. I would like to question this point as it is unclear how he is protecting the people and from whom. Most if not all psychiatrists would consider protection of these patients their duty and not that of a lay member of a Mental Health Review Tribunal-perhaps Professor Prins feels is he protecting the patients from psychiatrists.

(b) I would like to comment on the letter by $\mathrm{Dr}$ Kerry (Psychiatric Bulletin, 1991, 15, 641) that "legal representation may break the mould". In good clinical practice patients are not detained in hospital for longer than is essential for their treatment. Discharge prior to that may well contribute to less than total recovery or control of symptoms and a higher rate of subsequent breakdown. Furthermore, he comments that "the order may be discharged perhaps after a delay" etc. In my view and experience, this is an appalling practice, and may result in patients being discharged after a delay during which time they are not reviewed by the MHRT and may even have deteriorated but must be discharged as per Tribunal instructions. This is hardly fair or appropriate for either patient or doctor. He claims "every patient should have the same right" and this might be true in an ideal world. However, under the current MHA, this is not and cannot be the case. Some groups are discriminated against (particularly those with mental handicap) and this seems set to continue until such time as the current Act is completely reviewed.

(c) I agree with the comments by Dr Azuonye and Dr Campbell (Psychiatric Bulletin, 1991, $15,577)$ that the functions and outcome of the changes in the MHA ought to be reviewed. There certainly does seem to be recent research (Joyce et al and O'Dwyer et al-Psychiatric Bulletin, 1991, 15, 224-226) on the outcome of those detained under the Act; perhaps as Dr West suggests, the role of the independent psychiatrist could be extended so that he either replace the Tribunal system in its entirety or an assessment by the independent psychiatrist of applications for MHRTs be included in order to ensure that while "hopeless" cases are reviewed regularly they may not necessitate stress to the patient or expense to the system of a full MHRT.

I feel that the system of Tribunals and Appeals of those detained under the Act needs a total review and an assessment with regard to its cost effectiveness and alternative methods of appealing against detention orders needs to be considered urgently.

JANE O'DWYER

Meanwood Park Hospital

Leeds LS6 4QB

\section{Mental Health Review Tribunals}

\section{DeAr Sirs}

We would like to respond briefly to Dr West's comments (Psychiatric Bulletin, 1991, 15, 641) to our original letters (loc cit). Dr West has misunderstood the comment concerning treatment and no further comment is necessary if readers examine Prins' original letter. As to the other points he makes. First, if he does not agree with a reduction in his service budget he should protest in the appropriate place, not expect other budgets to be reduced. Second, any hidden costs should be allowed for in over-all planning (as for example in consultant contracts). Third, for the reasons given in our earlier letters we were dismayed to find $\mathrm{Dr}$ West describing 